\title{
JORNALISMO, CIÊNCIA E INTERDISCIPLINARIDADE: NOTAS SOBRE O INFORMAR E PRODUZIR CONHECIMENTO
}

JOURNALISM, SCIENCE, AND INTERDISCIPLINARITY: NOTES ON INFORMING AND PRODUCING KNOWLEDGE

\section{Jeferson Bertolini}

\author{
Doutorando em Ciências Humanas pela Universidade Federal de Santa Catarina \\ Mestre em Jornalismo pela Universidade Federal de Santa Catarina \\ Bacharel em Comunicação Social/Jornalismo pela Universidade do Vale do Itajaí \\ E-mail: jefersonbertolini@gmail.com
}

\section{RESUMO}

Este artigo pensa o jornalismo no contexto da ciência e da interdisciplinaridade. O objetivo é dizer que, além de informar, o jornalismo produz conhecimento, como faz a ciência. O texto aponta as faces inter, multi e transdisciplinar do jornalismo. O manuscrito é baseado em levantamento bibliográfico e observação. Conclui que o jornalismo tem pelo menos duas características em comum com a ciência: a produção de conhecimento e a busca pela verdade.

Palavras-chave: Jornalismo. Ciência. Interdisciplinaridade

\begin{abstract}
This article thinks journalism in science and interdisciplinarity. The text says that, in addition to informing, journalism produces knowledge, as does science. The text points out the inter-sided, multi and interdisciplinary journalism. The manuscript is based on literature review and observation. It concludes that journalism has at least two features in common with science: the production of knowledge and the search for truth.
\end{abstract}

Keywords: Journalism. Science. Interdisciplinarity

\section{INTRODUÇÃO}

O jornalismo é uma atividade que, à primeira vista, existe só para informar. Nesse sentido, sua principal função é fornecer informações de qualidade para que as pessoas sejam livres e se autogovernem (KOVACH \& ROSENSTIEL, 2003). Mas é possível atribuir a ele outra finalidade: produzir conhecimento. 
Indispensável ao desenvolvimento das sociedades desde a Antiguidade, quando os gregos se reuniam em mercados públicos para contar e ouvir notícias, o jornalismo produz conhecimento sobretudo quando deixa de divulgar o saber produzido pelos outros e passa a criar um conhecimento novo, autêntico e independente.

Park ([1945] 2008) entende que o jornalismo produz conhecimento pelas notícias. Ele coloca a notícia entre o conhecimento formal (knowldge about) e o conhecimento não sistemático, intuitivo ou de senso comum (acquaintance with).

Genro Filho ([1989] 2012), articulando as categorias universal, particular e singular de Georg Hegel (1770-1831), considera o jornalismo "uma forma de conhecimento cristalizada no singular". "Para o jornalismo, a singularidade, além de não ser arbitrária, é um ponto de chegada que coincide com a superação do particular e do universal" (GENRO FILHO, 2012, p. 168).

Meditsch (1997) vê o jornalismo como "uma forma de conhecimento de direito próprio". “Ao se deixar de considerar o jornalismo apenas como um meio de comunicação para considerá-lo como um meio de conhecimento, estará se dando um passo no sentido de aumentar a exigência sobre os seus conteúdos" (MEDITSCH, 1997, p. 13).

Produzir conhecimento é um termo que costuma ser associado à ciência, a atividade cuja finalidade básica é a produção de conhecimento (HARDT-DAVIS et al, 2014). Nota-se, portanto, que jornalismo e ciência têm algo em comum.

Este artigo pensa o jornalismo no âmbito da ciência moderna ${ }^{2}$. Interessa, principalmente, abordá-lo no contexto da interdisciplinaridade, da multidisciplinaridade e da transdisciplinaridade. Trata-se de três termos em voga no campo científico, sobretudo nas ciências sociais e humanas.

O texto baseia-se em levantamento bibliográfico, básico ao trabalho científico porque permite ao pesquisador conhecer o que já se estudou sobre o assunto (FONSECA, 2002), e em observação direta, que possibilita ao pesquisador assistir ao fenômeno estudado e registrar suas impressões onde mais lhe convier (ABRAMO, 1979).

O manuscrito está dividido em oito sessões. A primeira traz um resumo histórico do método científico. A segunda trata da inter-relação entre campos científicos. A terceira faz uma breve trajetória da interdisciplinaridade. A quarta relaciona interdisciplinaridade ao pensamento complexo (MORIN, 1996). A quinta aponta diferenças entre inter, multi e transdisciplinaridade. A sexta opõe interdisciplinaridade e especialização. A sétima apresenta duas iniciativas para tonar o jornalismo uma ciência. A oitava aponta as faces inter, multi e transdisciplinar do jornalismo.

$\mathrm{O}$ artigo conclui que o jornalismo tem pelo menos duas características em comum com a ciência: a produção de conhecimento e a busca pela verdade. O texto também conclui que o jornalismo não precisa ser alçado ao campo científico e ter status de ciência para ser socialmente relevante. 


\section{A CIÊNCIA E O MÉTODO CIENTÍFICO: BREVE HISTÓRICO}

A ciência pode ser entendida como o recurso por meio do qual o homem tenta, desde os primórdios, descobrir como o universo funciona. É uma busca permanente pela verdade, mesmo que provisória. Em resumo, a ciência se baseia no raciocínio, na observação e na experimentação (HARDT-DAVIS et al, 2014, p.12).

O filósofo grego Aristóteles (384-322 a.C.) é considerado um dos fundadores da ciência, apesar de, antes dele, ter havido na Grécia ${ }^{3}$ (Europa/Ocidente) e na Pérsia (Ásia/Oriente) estudos consistentes em física, matemática e astronomia. Aristóteles dizia que "a verdade está no mundo a nossa volta" (BUCKINGHAM et al, 2011, p. 58). E, diferentemente de outros pensadores gregos, que acreditavam que todo o conhecimento poderia ser obtido exclusivamente pelo raciocínio, considerava necessário (1) fazer medições empíricas e (2) observar. Também propôs a ideia de indução.

Aristóteles, no entanto, interpretou muitos fenômenos de forma equivocada. Ele afirmava, por exemplo, que objetos grandes caem mais depressa que os pequenos. Muitos de seus equívocos só foram percebidos no Renascimento (a partir do século XIV), com o enfraquecimento da influência da Igreja sobre a ciência (a velocidade da queda de objetos de pesos diferentes só foi esclarecida pelo físico italiano Galileu Galilei (1564-1642) em 1590).

O método científico só se desenvolveu após o Renascimento, a partir de nomes como Nicolau Copérnico (1473-153), o primeiro a dizer que o sol está no centro de tudo; William Gilbert (1544-1603), que impulsionou as navegações ao estudar o magnetismo da terra; Robert Boyle (1627-1691), que esclareceu o efeito de gases na natureza do espaço; Robert Hooke (1635-1703), que afirmava que todas as coisas são compostas por células; Isaac Newton (1642-1727), que dizia que a gravidade afeta tudo no universo, entre outros.

O nome mais expressivo da época ${ }^{4}$, no entanto, foi o do cientista inglês Francis Bacon (1561-1626). Ele dizia que todo o conhecimento deve vir da experiência (BUCKINGHAM et al, 2011, p. 110). Bacon não foi o primeiro a realizar experiências, mas foi o primeiro a colocar em primeiro plano a experiência prática na ciência - o inglês morreu de bronquite durante experimentos com neve como técnica para congelar frangos.

Bacon é considerado o pai da indução. Ele defendia a necessidade de testar uma nova teoria, em vez de só fazer observações. O inglês aceitava os ensinamentos da Igreja, mas frisava que a ciência deveria ser separada da religião. Bacon dizia que o cientista precisa romper barreias psicológicas para superar os ídolos da tribo (nossa tendência para generalizações), os ídolos da caverna (nossa tendência a ter preconcepções sobre a natureza, em vez de examiná-la), os ídolos do mercado (facilidade com que deixamos as convenções sociais distorcerem nossa experiência) e os ídolos do teatro (a influência dos dogmas filosóficos e científicos). 
O filósofo francês René Descartes (1596-1650), autor da obra clássica Discurso sobre o método (1637) e da célebre frase "Penso, logo existo", foi diretamente influenciado por Bacon. Mas ganhou mais notoriedade porque defendia a expansão do conhecimento e a compreensão do mundo, enquanto o inglês considerava que as aplicações práticas das descobertas científicas eram seu objetivo e ponto principal.

Descartes produziu um método de quatro fases de investigação científica, baseado em matemática: não aceite nada como verdade, a menos que seja evidente; divida problemas em partes simples; resolva os problemas passando dos simples aos complexos; verifique seus resultados (HARDT-DAVIS et al, 2014, p.332).

\subsection{A INTER-RELAÇÃO ENTRE OS CAMPOS CIENTÍFICOS}

Ao longo da história observa-se uma influência contínua de determinados campos científicos sobre outros. Nota-se, por exemplo, traços das ciências físicas e das ciências naturais ${ }^{5}$ sobre as ciências sociais e humanas, que nos interessam aqui. Um caso emblemático desse movimento percebe-se na Sociologia ${ }^{6}$, como segue.

O francês Auguste Comte (1798-1857), o primeiro a desenvolver um estudo da sociedade baseado em princípios científicos, buscou inspiração na física. Ele acreditava que, da mesma forma que as ciências físicas ajudaram a modificar nosso ambiente físico, o entendimento dos mecanismos da ordem social poderia levar a uma mudança social ${ }^{7}$.

No início dos estudos, Comte chamou seu processo de física social. Depois, simplificou para sociologia. Ele também fez uma análise detalhada das ciências naturais e de sua metodologia antes de propor que todos os ramos do conhecimento deveriam adotar princípios científicos e basear a teoria na observação.

Comte não foi o primeiro a tentar uma análise da sociedade humana. Mas foi o primeiro a determinar que isso era possível. Antes dele, Adam Smith (1723-1790) tentou explicar as mudanças sociais em termos econômicos; e Jean-Jacques Rousseau (1712-1778) quis o mesmo em termos políticos-filosóficos. Ninguém, até Comte, havia tentado englobar teorias políticas e econômicas (THORPE et al, 2015, p. 22).

Considerado o fundador da Sociologia, Comte foi comentado por outros nomes desse campo que o sucederam. O pensador alemão Karl Marx (1818-1883) discordava de Comte quando este usava a biologia como um modelo próximo às ciências sociais para pensar a sociedade como "um agrupamento de animais". Marx acreditava que a economia era o modelo adequado, porque pensava a vida como uma eterna luta de classes, na qual os donos do capital determinavam as condições de vida de quem não tinha posses. 
O sociólogo britânico Herbert Spencer (1820-1903), por sua vez, retomou a ideia da biologia ao propor um modelo orgânico às ciências sociais. Ele cunhou a frase "sobrevivência do mais apto"; acreditava que as sociedades seguem os princípios evolucionários do corpo humano, indo de estados simples a estados complexos, e que só sociedades mais fortes sobrevivem e crescem (THORPE et al, 2015, p. 334). Em parte, Spencer se inspirou na teoria das espécies do naturalista inglês Charles Darwin (1809-1882).

O sociólogo francês Émile Durkheim (1858-1917) foi influenciado por Spencer. Durkheim passou a pensar a sociedade como o corpo humano: ela tem partes, necessidades e funcionamentos inter-relacionados. Ele sustentava a ideia funcional de Spencer sobre partes separadas servindo a um propósito, mas enfatizava a noção de que a sociedade era maior que a soma de seus elementos. Durkheim defendia que a base para o estudo sociológico deveria ser aquilo que chamava de fatos sociais (uma espécie de realidade fora dos indivíduos) que poderiam ser verificados empiricamente ${ }^{8}$.

O exemplo pontual da Sociologia mostra como o conhecimento produzido por determinado campo científico (ou disciplina) possibilita o aparecimento ou a consolidação de outro campo científico. As zonas que esses diferentes campos têm em comum (aquilo que está contido no interior de dois ou mais) é a essência da interdisciplinaridade, tema da próxima sessão.

\section{INTERDISCIPLINARIDADE: ORIGEM DO TERMO}

A origem do termo interdisciplinaridade não é precisa. Klein (2005) diz que o termo surgiu no início do século XX, na esteira de reformas curriculares de universidades dos Estados Unidos e nos relatórios do Social Science Research Council.

Fazenda (1999) sustenta que o movimento surgiu na Europa, principalmente na França e na Itália, na década de 1960, a reboque dos movimentos estudantis (eles pediam um novo estatuto de universidade e de escola frente às propostas educacionais da época).

No Brasil, a interdisciplinaridade apareceu no final dos anos 1960. Como observa Fazenda (ibid), era vista como um modismo. A autora divide os primeiros estudos sobre interdisciplinaridade em três momentos: busca por construção epistemológica (anos 1970); explicitação das contradições epistemológicas (anos 1980); e construção de nova epistemologia, própria da interdisciplinaridade (anos 1990).

Leis (2011) diz que o termo ganhou força na década de 1940, e que desde então se apresenta como tema central do trabalho científico.

Minayo (2010) argumenta que a natureza interdisciplinar surgiu na Grécia Antiga, quando os sábios formularam a ideia do Uno e do Múltiplo, mostrando que a Filosofia, a Matemática, as Letras e as Artes deveriam compor a formação de um intelectual. 


\subsection{INTERDISCIPLINARIDADE E PENSAMENTO COMPLEXO}

Em um ponto há consenso: a interdisciplinaridade tem relação com o pensamento complexo, aquele que "enfrenta a desordem e a incerteza" (MORIN, 1996).

No fundo gostaríamos de evitar a complexidade, de ter ideias simples, leis simples e fórmulas simples para compreender e explicar o que ocorre ao nosso redor e em nós. Mas como essas fórmulas simples e essas leis simples são cada vez mais insuficientes, estamos confrontados com o desafio da complexidade (Ibid, p. 274).

Morin (ibid) diz que "há complexidade onde quer que se produza um emaranhamento de ações, interações e retroações", e que "esse emaranhamento é tal que nem um computador poderia captar todos os processos em curso".

O autor lembra que tal complexidade tem a ver com a obra do pensador francês Blaise Pascal (1623-1662). Pascal pregava que "todas as coisas são ajudadas e ajudantes, todas são mediatas e imediatas, e todas estão ligadas entre si por um laço que conecta umas às outras, inclusive as mais distantes".

Minayo (2010) observa que o pensamento complexo é fundamental para se entender a interdisciplinaridade. "É imprescindível o pensamento complexo para definirmos um objeto, e para buscarmos seu rumo e sua compreensão interdisciplinar."

A autora enumera quatro características gerais da pesquisa interdisciplinar: 1) uma disciplina terá prioridade sobre as outras por ser a que tem mais tradição, história e acúmulo de conhecimento sobre o assunto; 2) esse predomínio não pode anular a contribuição das outras disciplinas; 3) o trabalho interdisciplinar nunca deve pospor a contribuição que vem de uma disciplina; 4) na articulação entre disciplinas é preciso que cada uma das áreas apresente conceitos e teorias capazes de ampliar e complexificar a compreensão do objeto.

\subsection{INTERDISCIPLINARIDADE, MULTIDISCIPLINARIDADE E TRANSDISCIPLINARIDADE}

Apesar de frequentemente se considerar interdisciplinaridade, multidisciplinaridade e transdisciplinaridade como sinônimos, há diferença entre os termos.

A interdisciplinaridade é o processo que busca pontos comuns em mais de um campo científico. Ocorre naquele espaço em que A está contido em B, e B está contido em A.

Minayo (2010, p. 441) diz que "a interdisciplinaridade constitui uma articulação de várias disciplinas em que o foco é o objeto, o problema ou o tema complexo, para o qual não basta a resposta de uma só". Ela avalia que "a interdisciplinaridade não é um método novo: é uma estratégia eficiente para a compreensão, interpretação e explicação de temas complexos" da atualidade. 
Leis (2011) entende que a interdisciplinaridade é um processo de resolução de problemas que, por serem muito complexos, não podem ser trabalhados por uma disciplina.

Raynault (2011) considera que a interdisciplinaridade, longe de ser doutrina ou ideologia, se caracteriza por gerar constante dúvida e estar em permanente construção. O autor avalia que a interdisciplinaridade, longe de ser doutrina ou ideologia, se caracteriza por gerar constante dúvida e estar em permanente construção. Ele entende que o pensamento racional científico e os instrumentos conceituais e metodológicos que usamos para conhecer o mundo nunca deixarão de evoluir e de se transformar no decorrer de nossa história.

Pombo (2007, p. 1) avalia que "ninguém sabe ao certo o que é interdisciplinaridade. Nem as pessoas que a praticam, nem as que a teorizam, nem aquelas que a procuram definir". Para a autora, "não há nenhuma estabilidade a este conceito" e atualmente "encontra-se as mais díspares definições. Além disso, a palavra tem sido usada, abusada e banalizada".

Para Pombo (ibid, p. 6-7), a interdisciplinaridade é "um conceito que invocamos sempre que nos confrontamos com os limites do nosso território de conhecimento, sempre que topamos com uma nova disciplina cujo lugar não está traçado no grande mapa dos saberes, sempre que nos defrontamos com um problema cujo princípio de solução sabemos exigir o consumo de múltiplas e diferentes perspectivas". A autora destaca que, em contexto epistemológico, “a interdisciplinaridade tem a ver com as práticas de transferência de conhecimento entre disciplinas".

Krischke (2010, p. 12) entende que "não existe uma única proposta para o método interdisciplinar". "Há várias propostas diferentes, algumas até divergentes, embora todas tenham alguma utilidade, dependendo do tema e da intenção do pesquisador."

A multidisciplinaridade consiste na sobreposição de disciplinas. Não há interação entre elas. Não há zonas comuns. Só justaposição. A multidisciplinaridade também é chamada de pluridisciplinaridade. Um exemplo cotidiano seria a formação de uma equipe com psiquiatras, policiais, sociólogos, assistentes sociais, entre outros, para discutir a violência urbana e o consumo de drogas em determinada cidade.

Para Minayo (2010), a multidisciplinaridade "constitui uma justaposição de disciplinas, cada uma com suas teorias e metodologias próprias". Para Leis (2011), multidisciplinaridade não implica integração, só sobreposição dos diversos conhecimentos disciplinares convocados para determinado estudo.

A transdisciplinaridade é o mais avançado dos três termos. Prevê o surgimento de um produto ou evento totalmente novo a partir da interação entre dois ou mais campos científicos. Transcende o estar contido da interdisciplinaridade e a justaposição da multidisciplinaridade. Transdisciplinar seria juntar A com B e perceber a criação de X. 
Minayo (2010) entende que a transdisciplinaridade é "o produto final da interdisciplinaridade", a "ação resultante da capacidade que nós temos de ultrapassar as fronteiras das disciplinas pelo investimento articulado e a combinação das diferentes disciplinas em jogo, num processo de investigação que inclui articulação de teorias e conceitos, métodos e técnicas". Leis (2011) avalia que a transdisciplinaridade privilegia a dimensão teórica, tentando transcender as disciplinas na direção de conceitos e teorias comuns a todos os campos.

Pombo (2007) lembra que inter, multi e transdisciplinaridade têm em comum a raiz disciplina, que ela separa em três ramos: ramo do saber (como a matemática e a biologia); componente curricular (disciplinas escolares que derivam do ramo do saber); conjunto de normas (regulam determinada atividade, como a disciplina militar).

\subsection{INTERDISCIPLINARIDADE X ESPECIALIZAÇÃO}

A interdisciplinaridade é o oposto da especialização, um movimento também comum na academia. A especialização tem base em René Descartes (1596-1650) e Galileu Galilei (1564-1642). Ambos defendiam a necessidade de dividir o objeto de estudo para estudar finamente os seus objetos constituintes e, depois, recompor o todo a partir daí. Ou seja, acreditavam que conhecendo bem a parte, poderiam conhecer o todo.

Muitos estudiosos criticam a especialização. Hilton Japiassu (1976), citado por Minayo (2010), diz que o "especialista é aquele que possui um conhecimento cada vez mais extenso relativo a um domínio cada vez mais restrito. $\mathrm{O}$ triunfo da especialização consiste em saber tudo sobre nada”. Ortega y Gasset (1929), citado por Pombo (2007), avalia que “o especialista não é um sábio porque ignora formalmente tudo quanto não entra na sua especialidade; mas também não é um ignorante porque é um homem de ciência. Teremos de dizer que é um sábio-ignorante”.

\section{JORNALISMO: DUAS INICIATIVAS A CAMINHO DA CIÊNCIA}

No formato atual, o jornalismo surgiu no século 17, na Europa, com o aparecimento dos primeiros jornais ${ }^{9}$. A atividade se expandiu no século seguinte, com a industrialização: os sistemas de impressão melhoraram, permitindo aumentar as tiragens, e a população que começava a chegar às cidades em busca de trabalho formava um público leitor.

Mas, se considerada a essência da atividade, de informar, pode-se dizer que o jornalismo nasceu na Grécia Antiga, com Heródoto ${ }^{10}$, que fazia viagens entre Grécia (Europa) e Pérsia (Ásia) para registrar os grandes feitos da humanidade. 
O jornalismo não é reconhecido como ciência, apesar de ter havido pelo menos dois grandes movimentos nessa direção: o primeiro com o sociólogo alemão Max Weber, em 1910; e o segundo com o discípulo dele, Otto Groth, em 1960.

Weber propôs a criação da Sociologia da Imprensa. Seria nos mesmos moldes da Sociologia do Trabalho, da Sociologia das Religiões e de outras especializações da Sociologia geral. O objetivo de Weber era entender as relações econômicas e políticas a partir da imprensa. O autor também queria compreender os efeitos do fato de a imprensa ser a única instituição a tornar públicos determinados fatos em detrimento de outros. "De nossa parte, teremos que investigar, sobretudo, as relações de poder criadas pelo fato específico de que a imprensa torne públicos determinados temas e questões" (WEBER, 2015, p. 15).

Weber definiu dois temas prioritários: o negócio do jornal, que envolvia também organizações e trabalhadores, e o espírito desse negócio, que focava mais o viés político e a opinião pública. Ele reuniu em torno do projeto grandes nomes da Sociologia, e chegou a elaborar orçamento aos estudos. Mas o projeto não saiu do papel. Até hoje estudiosos do jornalismo lamentam esse desfecho. "O programa de pesquisa sobre a imprensa de Weber é, de muitos pontos de vista, uma oportunidade desperdiçada” (BASTIN, 2013, p, 23).

Groth, por sua vez, propôs uma ciência dos jornais. O objeto dessa nova ciência, que teria o mesmo status de Economia e Administração, por exemplo, seriam os jornais. Groth definiu quatro elementos básicos aos jornais: periodicidade, atualidade, universalidade e difusão. Para o autor, periodicidade não se limita ao tempo de publicação de um determinado número, mas como o jornalismo interfere no ritmo de vida das pessoas, representando, inclusive, comportamentos e padrões econômicos, políticos, sociais, culturais e psicológicos. A universalidade refere-se à abrangência e à heterogeneidade com que o jornalismo seleciona e apresenta os fatos. A atualidade diz respeito aos fatos novos. A difusão corresponde ao acesso do público à informação. A proposta da ciência dos jornais também não saiu do papel.

As iniciativas de Weber e Groth não levaram o jornalismo ao âmbito científico. Entretanto, não se pode negar que o jornalismo tem uma característica comum com a ciência: produzir conhecimento.

Como observa Meditsch (1997, p. 11), o jornalismo é uma forma de produção de conhecimento, e não um simples instrumento para transmitir conhecimentos produzidos por outros. O autor diz que não são os argumentos dos jornalistas que sustentam este ponto de vista, mas "os desenvolvimentos recentes nas áreas da epistemologia, teoria do discurso, sociologia do conhecimento ${ }^{11}$ e psicologia da cognição, disciplinas que possuem um respeitável embasamento científico e filosófico". 
Ao se deixar de considerar o jornalismo apenas como um meio de comunicação para considerá-lo como um meio de conhecimento, estará se dando um passo no sentido de aumentar a exigência sobre os seus conteúdos. Conhecimento implica em aperfeiçoamento pela crítica e requer rigor. Considerar o jornalismo como modo de conhecimento implica também em aumentar a exigência sobre a formação profissional dos jornalistas, que deixam de ser meros comunicadores para se transformarem em produtores e reprodutores de conhecimento (Ibid).

Meditsch (1997, p. 12) acrescenta que "o conhecimento da realidade é uma questão tão vital para os indivíduos e para as sociedades que, se o jornalista não é apenas quem comunica o conhecimento, mas também quem o produz e o reproduz, deve estar submetido a um controle social e a uma avaliação técnica mais próxima e mais permanente".

Park (2008) observa que, embora a notícia seja uma forma mais primitiva e elementar de comunicação que a ciência, a notícia não pode de jeito nenhum ser substituída por ela. "Pelo contrário, a importância da notícia tem crescido consistentemente com a expansão dos meios de comunicação e com o crescimento da ciência" (PARK, 2008, p. 69).

\subsection{AS FACES INTER, MULTI E TRANSDISCIPLINAR DO JORNALISMO}

Ao produzir conhecimento, o jornalismo teria uma característica em comum com a ciência. Afinal, como observa Hardt-Davis (et al, 2014), a produção de conhecimento é função básica da ciência desde os primórdios. Nesse contexto, convém perguntar: o jornalismo estaria em sintonia com a interdisciplinaridade, com a multidisciplinaridade ou com a transdisciplinaridade? A resposta depende do ângulo que se observa a questão:

O jornalismo poderia ser considerado interdisciplinar quando constrói um saber com aquilo que está em A e B. Aqui é importante lembrar de Pombo (2007), para quem a interdisciplinaridade é um conceito que invocamos sempre que nos confrontamos com os limites do nosso território de conhecimento, sempre que topamos com uma nova disciplina cujo lugar não está traçado no grande mapa dos saberes.

O jornalismo poderia ser considerado multidisciplinar quando se limita a empilhar conhecimentos de duas ou mais disciplinas diferentes. Não constrói um discurso próprio. Aqui é importante lembrar de Minayo (2010), para quem a multidisciplinaridade só constitui uma justaposição de disciplinas, cada uma com suas teorias e metodologias próprias.

O jornalismo poderia ser considerado transdisciplinar quando cria um saber novo, que vai além das zonas de intersecção entre A e B e que ultrapassa o simples empilhamento de conhecimentos. Aqui vale retomar Minayo (2010), para quem transdisciplinaridade é "o produto final da interdisciplinaridade". 
O jornalismo pode ser pensado em um desses três termos do ponto de vista epistemológico. Não se pode pensá-lo inter, multi ou transdisciplinar pelo fato de ele, na produção de conhecimento, valer-se de técnicas usadas pela ciência, como as entrevistas ${ }^{12}$.

\section{CONSIDERAÇÕES FINAIS}

O jornalismo, considerando sua essência, de informar, é uma atividade que surgiu mais de quatro séculos antes de Cristo, com Heródoto (484-425 a.C.). O grego tornou-se conhecido como o primeiro repórter do mundo (KAPUSCINSKI, 2006) por percorrer a Grécia e a Pérsia atrás de boas histórias para contar. Considerando o formato que conhecemos hoje, o jornalismo é uma atividade que se desenvolveu a partir do século 17, com o surgimento dos primeiros jornais.

A ciência, também considerando sua essência, de produzir conhecimento, também surgiu na Grécia Antiga, com Aristóteles (384-322 a.C.). O grego foi o primeiro filósofo a dizer que o conhecimento não poderia vir exclusivamente da razão. Considerando o formato que conhecemos hoje, a ciência se desenvolveu a partir do século 16, com o Renascimento e a consequente diminuição da influência da Igreja nas explicações sobre a vida.

Seja em essência, seja no formato atual, jornalismo e ciência são atividades diferentes, com objetivos diferentes. Mas ambos têm pelo menos duas características em comum: a produção de conhecimento e a busca pela verdade.

O jornalismo produz conhecimento quando deixa de simplesmente divulgar o conhecimento produzido pelo outros e passa a construir um discurso próprio, original e independente, a partir dos outros ou de si próprio. O jornalismo busca a verdade sobretudo em sua esfera cotidiana (a verdade jornalística opera no registro apuração/fato/versões).

A ciência produz conhecimento quando faz descobertas. Ela também busca a verdade em suas atividades cotidianas (a verdade científica opera no registro experiência/verdadeiro/falso).

Para finalizar, cabe ressaltar que o jornalismo não precisa ser levado ao status de ciência para ser socialmente relevante. Ele é suficientemente importante quando informa.

\section{NOTAS}

1 Em Hegel, o universal refere-se à pressuposição da racionalidade primeira e constitutiva do real. O particular é a negação da racionalidade universal, indeterminada e abstrata. O singular é a particularidade restituída da plena inteligibilidade do universal; é o conceito realizado, é o momento terminal da estrutura dialética. Estas três categorias ajudam a compreender a dialética hegeliana. Hegel dizia que toda noção, ou tese, tem em si uma contradição, ou antítese, que só é solucionada pelo 
surgimento de uma noção nova, a síntese. Hegel se inspira em Immanuel Kant (1724-1804), para quem os processos básicos por meio dos quais o pensamento funciona e as estruturas básicas da consciência são a priori - existem antes da experiência.

2 A nova ciência, diz o professor João Eduardo Pinto Basto Lupi, do Programa de Pós-Graduação Interdisciplinar em Ciências Humanas da Universidade Federal de Santa Catarina (UFSC), "tem respeito por outras formas de ciência, por ciências femininas, por ervas, por conhecimentos práticos, por ciências orientais". Nela "há uma integração geral e holística". Há também "o fim do preconceito acadêmico: ‘se eu sei, você também sabe'”. Dito em sala de aula em 11 de junho de 2014.

3 A título de exemplo podem ser destacados os estudos de Tales de Mileto (624-546 a.C.), o primeiro a dizer que eclipses do sol podem ser previstos, e os de Empédocles (490-430 a.C.), que dizia que toda matéria é composta por quatro raízes (mais tarde chamados de elementos): terra, ar, fogo e água (HARDT-DAVIS et al, 2014).

4 O período da expansão do conhecimento após o Renascimento ficou conhecido como Revolução Científica (BUCKINGHAM et al, 2011).

5 As ciências naturais também vêm sendo, ao longo da história, determinantes às ciências da saúde. Prova emblemática é o DNA humano, que norteia tratamentos na área médica. O DNA foi apresentado ao mundo em 1953, em artigo publicado na Nature pelo biólogo James Watson. Watson valeu-se de uma longa trajetória de estudos, sobretudo os do biólogo alemão Walter Flemming (1880, descobridor dos cromossomos) e os de Gregor Mendel (1900, detalhou a hereditariedade a partir de estudos com ervilhas) (HARDT-DAVIS et al, 2014).

6 A Sociologia só foi aceita como disciplina independente, uma ciência social distinta da Filosofia, na segunda metade do século XIX (THORPE et al, 2015).

7 Comte escreveu em época de mudanças sociais profundas por conta da Revolução Francesa (1789-1799) e da Revolução Industrial (a partir de 1750).

8 Durkheim pensava a sociedade moderna ligando-a à industrialização (à divisão social dela advinda), quando Karl Marx ligava-a ao capitalismo e Max Weber (1864-1920) à racionalização (THORPE et al, 2015, p. 36).

9 Há certa divergência, mas em geral aceita-se o Aviso de Augsburg, publicado em 1609, na Alemanha, como o primeiro jornal do mundo (BRIGGS \& BURKE, 2006).

${ }^{10}$ Heródoto nasceu em Halicarnasso, cidade portuária da Ásia Menor, por volta de 485 a.C. Em meados de 450 a.C., mudou-se para Atenas.Viajou muito ao longo da vida, e escreveu História. Acredita-se que tenha sido sua única obra. Ele dedicou toda a vida à tarefa de tentar encontrar repostas a perguntas históricas, como "por que os homens travam guerras entre si" e "o que move o homem". O objetivo de Heródoto, como o próprio escreveu em História, na página 43, era "evitar que os vestígios das ações praticadas pelo homem se apaguem com o tempo" e que "as grandes e maravilhosas explicações dos Gregos, assim como as dos Bárbaros, permanecessem ignoradas". Ele deixa claro que o material recolhido foi testemunhado por ele ou terceiros e que seu objetivo era ser o mais preciso possível, tal como fazem ou deveriam fazer os repórteres dos tempos atuais. Algumas de suas expressões em História deixam isso bem claro: "Estes são os costumes dos persas, como pude observar. As perquirições que realizei em torno de suas origens convenceram-me de que foi assim que tudo aconteceu" (p.218). Na versão original, o material apurado por Heródoto era acessível a poucos especialistas em grego antigo capazes de ler a um tipo específico de relato, que parecia uma palavra sem fim e ocupava rolos e mais rolos de papiro. "Não havia o costume de separar palavras ou frases específicas, assim como não se conhecia o conceito de títulos e capítulos", escreveu Hammer na apresentação. No formato de livro que conhecemos hoje, História só foi oficialmente publicado em 1954, com distribuição no ano seguinte. 
${ }^{11}$ Refere-se a um campo especial da Sociologia que trata de toda a gama de produtos culturais (ideias, ideologias, crenças jurídicas e éticas, filosofia, ciência, tecnologia). Interessa-se pelas relações entre o conhecimento e os outros fatores existenciais da cultura e da sociedade (MERTON, 1968, p. 553).

${ }^{12}$ No jornalismo moderno, as entrevistas começaram a ser usadas naquilo que Marcondes (2000) chama de segunda fase do jornalismo (o jornalismo de informação, de 1830 a 1900). Nessa época empresas jornalísticas cresceram e se aproximaram do capitalismo: surgiram as divisões de trabalho nas redações, com a separação entre departamentos de gestão, editorial e reportagem. Nas ciências sociais, para efeito de comparação, as entrevistas começaram a ser usadas em 1930, segundo Godoi e Mattos (2006). Eles citam três características principais que a diferem de uma conversa comum: 1) na entrevista, a participação do entrevistado e do entrevistador conta com expectativas explícitas: um de falar e o outro de escutar; 2) o animador anima constantemente o entrevistador a falar, sem contradizê-lo; 3) aos olhos do entrevistado, o encarregado de organizar e manter a conversação é o entrevistador. Outras ferramentas usadas por cientistas sociais, com seus devidos enfoques e profundidade, mas que também soam familiares para o jornalismo são: a análise de conteúdo, que apareceu para a academia em 1915; os grupos focais de estudo são da mesma época; a etnografia tem raiz no século 19, mas na universidade brasileira só começou a ser usada nos anos 1970 .

\section{REFERÊNCIAS}

ABRAMO, Perseu. Pesquisa em ciências sociais. In: Pesquisa social, projeto e planejamento. São Paulo, Queiroz Editor, 1979.

BASTIN, Gilles. The press in the light of modern capitalism: a planned survey by Max Weber on newspapers and journalism. Max Weber Studies, v. 13, n. 2, 2013.

BRIGGS, Asa; BURKE, Peter. Uma história social da mídia: de Gutenberg à internet. 2.ed. Rio de Janeiro: Zahar, 2006.

BUCKINGHAM, Will (et. al.). O livro da filosofia. São Paulo: Globo Livros, 2011.

FAZENDA, Ivani. Interdisciplinaridade: história, teoria e pesquisa. 4 ed. Campinas: Papirus, 1999.

FONSECA, João José. Metodologia da pesquisa científica. Fortaleza: UEC, 2002.

GENRO FILHO, Adelmo. O segredo da pirâmide: para uma teoria marxista do jornalismo. Florianópolis: Insular, 2012.

GODOI, Christiane; MATTOS, Pedro Lincoln. Entrevista qualitativa: instrumento de pesquisa e evento dialógico. In: Pesquisa qualitativa em estudos organizacionais. Saraiva, 2006.

GROTH, Otto. O poder cultural desconhecido: fundamentos da ciência dos jornais. Tradução de Liriam Sponholz. Petrópolis: Vozes, 2011.

HART-DAVIS, Adam (et. al.). O livro da ciência. São Paulo: Globo Livros, 2014.

KAPUSCINSKI, Ryszard. Minhas Viagens com Heródoto: entre a história e o jornalismo. São Paulo: Companhia das Letras, 2006. 
KLEIN, Julie Thompson. Humanities, culture and interdisciplinarity: the Changing American Academy. Albany: State University of New York Press, 2005.

KOVACH, Bill; ROSENSTIEL, Tom. Os elementos do jornalismo: o que os jornalistas devem saber e o público exigir. 2.ed. São Paulo: Geração Editorial, 2003.

KRISCHKE, Paulo. Interfaces temáticas: origens e diferenças. In: A aventura interdisciplinar: quinze anos de PPGICH/UFSC. Blumenau: Nova letra, 2010.

LEIS, Hector Ricardo. Especificidades e desafios da interdisciplinaridade nas ciências humanas. In: PHILIPPI Jr., Arlindo e SILVA NETO, Antônio (editores). Interdisciplinaridade em Ciência, Tecnologia e Inovação. Barueri, SP. Manole, 2011.

MARCONDES FILHO, Ciro. Comunicação e Jornalismo: a saga dos cães perdidos. São Paulo: Hacker Editores, 2000.

MEDITSCH, Eduardo. O Jornalismo é uma forma de conhecimento? Conferência feita nos Cursos da Arrábia, Universidade de Verão. Portugal, 1997.

MERTON, Robert. Sociologia: teoria e estrutura. São Paulo: Mestre Jou, 1968.

MINAYO, Maria Cecília de Souza. Disciplinaridade, Interdisciplinaridade e Complexidade. Revista Emancipação. Ponta Grossa, 2010.

MORIN, Edgar. Epistemologia da Complexidade. In: SCHNITMAN, D.F. (org.) Novos Paradigmas, cultura e subjetividade. Porto Alegre: Artes Médicas, 1996.

PARK, Robert. A notícia como forma de conhecimento (1945). In. BERGER, Christa; MAROCCO, Beatriz. (orgs). A Era Glacial do Jornalismo. Porto Alegre: Sulina, 2008.

POMBO, Olga. Epistemologia da Interdisciplinaridade. Conferencia proferida no Colóquio Interdisciplinaridade, Humanismo e Universidade, promovido pela Cátedra Humanismo Latino, Porto, 2007.

RAYNAULT, Claude. Interdisciplinaridade: mundo contemporâneo, complexidade e desafios à produção e à aplicação de conhecimento. In: PHILIPPI Jr., Arlindo e SILVA NETO, Antônio (editores). Interdisciplinaridade em Ciência, Tecnologia e Inovação. Barueri, SP. Manole, 2011.

THORPE, Christopher (et. al.). O livro da sociologia. São Paulo: Globo livros, 2015.

WEBER, Max. Sociologia da Imprensa: um programa de pesquisa. Estudos em Jornalismo e Mídia, v. 2, n. 1, 2015. 